\title{
Feverfew in rheumatoid arthritis: a double blind, placebo controlled study
}

\author{
MARTIN PATTRICK, ${ }^{1}$ STAN HEPTINSTALL ${ }^{2}$ AND MICHAEL DOHERTY ${ }^{1}$ \\ From the ${ }^{1}$ Rheumatology Unit, City Hospital, and the ${ }^{2}$ Department of Medicine, University Hospital, \\ Nottingham
}

SUMMARY Feverfew, reputed by folklore to be effective in arthritis, has in vitro properties that could be beneficial in the control of inflammatory disease. Forty one female patients with symptomatic rheumatoid arthritis received either dried chopped feverfew (70-86 mg) or placebo capsules once daily for six weeks. Allocation was random and not known by patient or observer. Variables assessed included stiffness, pain (visual analogue scale), grip strength, articular index, full blood count, erythrocyte sedimentation rate, urea, creatinine, $C$ reactive protein, complement breakdown products (C3dg), rheumatoid factor titre, immunoglobulins (IgG, $\operatorname{IgA}$, IgM), functional capacity, and patient and observer global opinions. One patient (placebo) withdrew after three days and was not included in the analysis. Treatment and placebo groups (20 patients each) were well matched at entry. No important differences between the clinical or laboratory variables of the groups were observed during the six week period. This study therefore shows no apparent benefit from oral feverfew in rheumatoid arthritis.

Many patients with chronic, painful illness find conventional treatments unsatisfactory; adverse reactions or inadequate efficacy are common problems and patients may look for alternative forms of treatment. Herbal remedies have been popular since antiquity ${ }^{1}$ and have the attraction, at first glance, of being relatively inexpensive, 'natural', and free of adverse effects. In the late 1970s newspaper reports of the efficacy of feverfew (Tanacetum parthenium) provoked a resurgence of interest in this herb, alleged by the folklore to be beneficial in psoriasis, migraine, and arthritis. More recently, in vitro demonstration of inhibition of polymorphonuclear secretory activity by extract of feverfew provided a mechanism to support such anecdotal claims, ${ }^{2}$ and two clinical trials have shown feverfew to be beneficial in migraine. ${ }^{34} \mathrm{We}$ therefore undertook a prospective double blind, placebo controlled trial to investigate the possible clinical, anti-inflammatory effect of feverfew in patients with arthritis. Rheumatoid arthritis (RA) was chosen because of its recognised inflammatory component.

Accepted for publication 5 December 1988.

Correpondence to $\mathrm{Dr} M$ Pattrick, Rheumatology Unit, City Hospital, Nottingham NG5 1PB.

\section{Patients and methods}

The study was approved by the local ethical committee. Female patients under the age of 65 with classical or definite RA attending the rheumatology unit at the City Hospital, Nottingham were invited to participate. Each had inadequately controlled inflammatory joint symptoms and were being considered for a change of non-steroidal anti-inflammatory drug treatment or commencement of 'second line' treatment, or both. Forty one patients entered the study. Each was randomly allocated to receive either feverfew or matching placebo in identical red gelatin capsules taken once daily for six weeks. Capsules were prepared and contained either 70-86 mg (mean $76 \mathrm{mg}$ ) dried, powdered feverfew leaf (equivalent to 2-3 $\mu \mathrm{mol}$ parthenolide) or placebo (identically treated cabbage). One capsule of feverfew thus corresponded to two medium sized leaves. Patients were advised to store capsules in a domestic refrigerator $\left(4^{\circ} \mathrm{C}\right)$. Current non-steroidal antiinflammatory and analgesic treatment was maintained but not altered during the trial. Patients with deteriorating symptoms due to marked synovitis during the study period (unresponsive to other local measures) were offered a single intra-articular injection of steroid (triamcinolone hexacetonide 
$20 \mathrm{mg}$ ) as 'escape' at the three week review and the event recorded.

Patients were assessed at entry and at three and six weeks by a single observer. Clinical assessments at each visit included duration of early morning stiffness (min), inactivity stiffness (present/absent), pain $(10 \mathrm{~cm}$ visual analogue scale), grip strength (at $30 \mathrm{mmHg}$ : summated mean score for both hands), and Ritchie articular index. Patients were asked to report any untoward effects, which were then recorded. At 0 and 6 weeks haemoglobin, white cell count, platelet count, urea, creatinine, erythrocyte sedimentation rate, $\mathrm{C}$ reactive protein, immunoglobulins (IgG, $\operatorname{IgM}, \operatorname{IgA})$, latex fixation test, Rose-Waaler titre, and $\mathrm{C} 3$ degradation products (C3dg) were measured on venous blood, and the Steinbrocker functional capacity recorded. At six weeks separate global opinions (better, same, worse) were obtained from both patient and observer. Any adverse event was recorded.

Statistical comparison of incidence was by $\chi^{2}$ test with Yates's continuity correction; continuously variable data were compared by Student's paired $t$ test.

\section{Results}

One 63 year old patient (placebo) withdrew herself from the study after only three days because of light headedness. Complete data were obtained for 40 patients (20 in each group). At entry there was no significant difference between groups for age, disease duration, or seropositivity (Table 1): the placebo group did differ, however, in having a lower mean haemoglobin and creatinine concentration.

Comparison of findings at three weeks showed only an increased urea concentration in the feverfew group (mean (SD): 5.9 (1.7) $v 4.8(1.8) \mathrm{mmol} / \mathrm{l}$; $\mathrm{p}=0.040$ ): this, however, was not apparent at six weeks. Comparison of findings at six weeks showed differences that reached significance in only two indices: grip strength was increased in the feverfew group compared with the initial value in this group (110 (49) $v 99$ (35) $\mathrm{mmHg} ; \mathrm{p}=0.030)$ and compared with placebo at six weeks (110 (49) v 93 (32) $\mathrm{mmHg}$;

Table 1 Patient characteristics

\begin{tabular}{lcc}
\hline & $\begin{array}{l}\text { Feverfew } \\
(n=20)\end{array}$ & $\begin{array}{c}\text { Placebo } \\
(n=20)\end{array}$ \\
\hline $\begin{array}{l}\text { Mean age (years) } \\
\text { (range) }\end{array}$ & 52 & 53 \\
$\begin{array}{l}\text { Seropositivity } \\
\text { Mean disease duration (years) } \\
\text { (range) }\end{array}$ & $17-65)$ & $(28-65)$ \\
\hline
\end{tabular}

$\mathrm{p}=0 \cdot 047)$; serum IgG concentrations were increased compared with baseline in the feverfew group $(12 \cdot 3$ : (2.8) $v 11.6(2.7) \mathrm{g} / \mathrm{l} ; \mathrm{p}=0.025)$. There were nos differences between groups for the single assessmentso at six weeks.

Apart from the patient who was withdrawn only one other patient (feverfew) reported any adverse effect (minor ulceration and soreness of tongue $\xi^{\circ}$ responding to local measures).

\section{Discussion}

Aqueous and organic extracts of feverfew have variety of in vitro actions which might be expected to be beneficial in inflammatory disease. These include suppression of prostaglandin productionir (independent of inhibition of cycloxygenation $\left.{ }^{5}\right) \stackrel{+}{\rightarrow}$ inhibition of phospholipase, ${ }^{6}$ inhibition of leucocyte and platelet granule secretion and platelet aggregation $^{2}$; cytotoxicity against normal human fibroblast has also been shown. ${ }^{7}$ The properties of feverfew extracts have been attributed to the presence oto parthenolide and other sesquiterpene lactones. 80 These properties, in conjunction with the folklore prompted us to study the clinical effect of feverfew in patients with RA. We primarily sought sympto matic and functional benefit, rather than second lin\& effect, within the time scale reported in the folklor (improvement usually occurring within one to three weeks of regular usage ${ }^{910}$ ). Standard laborator investigations were additionally performed to asses? comparability between placebo and treatment groups, and to detect any in vivo anti-inflammatory effects that might be expected from the dramatic rapidly acting in vitro properties. ${ }^{25-7}$

This double blind trial, however, showed nథ. additional benefit from feverfew during the six wees period. Although 'significant' changes occurred i two of the factors examined (one in favour, one against feverfew), this was no more than expected by chance in a study examining 21 variabless Although it is possible that we gave an inadequate dose (two reports suggest up to $100 \mathrm{mg}^{11}$ to $125 \mathrm{mg}^{\mathrm{S}} \mathrm{S}$ daily for efficacy), most authors emphasise the quality rather than quantity of herb. ${ }^{9}$ One to two leaves daily is the usual dose discussed in folklore and an equivalent dose, as used in this study, has been reported to be effective in migraine. ${ }^{4}$ It is saiof that concomitant non-steroidal anti-inflammatory drugs or steroid may reduce the efficacy of feverfew. ${ }^{10}$ In practice, however, many patients use feverfew as a supplement to their conventional drug treatmen $\overrightarrow{\mathrm{e}}$ and it was considered unethical to withdraw anti inflammatory treatment completely for the purpose of this study. Indeed, the high incidence of intras articular steroid requirement at three weeks reflecto 
the poor disease control in these selected patients; similar injection requirements in both groups argue against such treatment being a confounding factor in the results.

Although feverfew extract is active in vitro and the preparation of feverfew used has been shown to be effective in migraine ${ }^{4}$ we have no direct evidence that it was absorbed from the gut in our patients with RA. Although not suggested by folklore, a slow acting, second line effect from feverfew cannot be excluded by this six week study. Equally, it does not exclude possible benefit for osteoarthritis and soft tissue lesions, for which self treatment with feverfew is probably most common.

The often extravagant claims for alternative treatments have not been investigated by many clinical trials. Those that have been published, however, have often failed to show efficacy. For example, Harpagophytum procumbens (Devil's claw) appears ineffective in RA, ${ }^{2}$ mussel extract (Seatone) produces dubious benefit in $\mathrm{RA},{ }^{13}$ and trials of homoeopathy in osteoarthritis ${ }^{14}$ and $\mathrm{RA}^{15}$ show little or no benefit, though design of some of these studies has been criticised. ${ }^{16} \mathrm{~A}$ possible exception to date is the reported benefit from fish oil in RA. ${ }^{17} 18$ Lack of evidence of efficacy has not lessened the attraction of herbal remedies, however, and there are over 2000 outlets in the United Kingdom for such products. Under the 1968 Medicines Act and 1984 Food Act prepacked remedies sold without claim for efficacy and loose herbs for home preparation of medicines do not require a product licence. The belief that herbal remedies are natural and free from side effects is attractive to some patients, but few products warn the user of potential toxicity. Some products are, however, toxic and some are contraindicated during pregnancy. ${ }^{19}$ Notwithstanding such difficulties many drugs in common use do derive from natural products, and it remains possible that there may be some validity in unsubstantiated claims. This question, however, can only be resolved by appropriate clinical trials.

We thank the Arthritis and Rheumatism Council for financial support. Professor J R A Mitchell for his helpful advice in formulation of this project. Drs A J Swannell and D H Bossingham for allowing us to include their patients. Mrs Sheila Green and Miss W Antoinette Groenewegen for help with the preparation and assay of the feverfew. Dr Brian Power and the staff of the department of botany at the University of Nottingham for cultivating the feverfew plants, and Mrs Caroline Bloomfield for secretarial assistance.

\section{References}

1 Eagle R. Herbs, useful plants. London: British Broadcasting Corporation. 1981.

2 Heptinstall S, White A, Williamson L. Mitchell J R A. Extracts of feverfew inhibit granule secretion in blood platelets and polymorphonuclear leucocytes. Lancet 1985; i: 1071-4.

3 Johnson E S. Kadam N P. Hylands D M. Hylands P J. Efficacy of feverfew as prophylactic treatment of migraine. $\mathrm{Br}$ Med $J$ 1985; 291: 569-73.

4 Murphy J J, Heptinstall S. Mitchell J R A. Randomised doubleblind placebo-controlled trial of feverfew in migraine. Lancet 1988; ii: $189-92$.

5 Collier H O, Butt N M. McDonald-Gibson N J. Saced S A. Extract of feverfew inhibits prostaglandin biosynthesis. Lancet 1980; ii: $922-3$.

6 Makheja A N. Bailey J M. A platelet phospholipase inhibitor from the medicinal herb feverfew (Tanacetum parthenium). Prostaglandins, Leukotrienes Med 1982; 8: 650-60.

7 Lee K-H, Huang E-S, Piantadosi C. Pagano J S. Geissman T A. Cytotoxicity of sesquiterpene lactones. Cancer Res 1971; 31: 1649-54.

8 Berry M I. Feverfew faces the future. Pharmaceutical Journal 1984; 232: 611-4.

9 Anonymous. Central Food Trader. 1984.

10 Hancock K. Newsheet of the International Feverfew Appreciation Society. Breaston. Derbyshire: International Feverfew Appreciation Society, 1984.

11 Pugh W J. What is the drug (if any) in the plant feverfew (Pyrethrum parthenium)? What are its therapeutic benefits? Br Med J 1985; 290: 925.

12 Grahame R. Robinson B V. Devil's claw (Harpagophytum procumbens): pharmacological and clinical studies. Ann Rheum Dis 1981; 40: 632.

13 Anonymous. Green-lipped mussel extract in arthritis [Editorial]. Lancet 1981; i: 85.

14 Shipley M, Berry H. Broster G. Jenkins M. Clover A. Williams I. Controlled trial of homoeopathic treatment of osteoarthritis. Lancet 1983; i: 97-8.

15 Gibson R G. Gibson S L M, MacNell A D. Watson Buchanan W. Homoeopathic therapy in rheumatoid arthritis: evaluation by double-blind clinical therapeutic trial. Br J Clin Pharmacol 1980; 9: 453-9.

16 Huston G. Salicylates and homocopathy. Br J Clin Pharmacol 1979: 7: $529-30$.

17 Kremar J M. Rynes R I. Bartholomew LE. Michalck A. Jabiz W. A double-blind placebo controlled crossover study of cicosapentenoic acid supplementation in active rheumatoid arthritis. Arthritis Rheum 1986; 29 (suppl): S11.

18 Sperling R I. Weinblatt M. Robin J-L, et al. Effects of dictary supplementation with marine fish oil on leukocyte lipid mediator generation and function in rheumatoid arthritis. Arthritis Rheum 1987: 30: 988-97.

19 Mills S. Dictionary of modern herbalism. Wellingborough. Northamptonshire: Thorsons, 1985. 